\title{
FUNCTIONAL OUTCOMES OF PROXIMAL ROW CARPECTOMY: 2-YEAR FOLLOW-UP
}

\author{
Luiz Garcia Mandarano-Filho ${ }^{1}$, Débora Schalge Campioto $^{1}$, Márcio Takey Bezuti ${ }^{1}$, Nilton Mazzer ${ }^{1}$, Cláudio Henrique Barbieri
}

\section{ABSTRACT}

Objective: To evaluate functional outcomes of patients submitted to proximal row carpectomy for the treatment of wrist arthritis. Methods: This is a retrospective study using wrist motion and grip strenght of patients diagnosed with Kienböck disease and scaphoid non-union surgically treated by this technique. Results: Eleven patients with 2-year follow-up were evaluated. Wrist motion (flexion, extension and ulnar deviation) and grip strength were significantly better from preoperative values. However, no difference in radial deviation was observed in these patients. Conclusion: Proximal row carpectomy provides an alternative option for treatment of wrist arthritis, resulting in better active range of motion and grip strength in the long run.

\section{Level of Evidence IV, Case Series.}

Keywords: Osteonecrosis. Carpal Bones/surgery. Pseudarthrosis.

Citation: Mandarano-Filho LG, Campioto DS, Bezuti MT, Mazzer N, Barbieri CH. Functional outcomes of proximal row carpectomy: 2-year follow-up. Acta Ortop Bras. [online] 2015;23(6):311-4. Available from URL: http://www.scielo.br/aob.

\section{INTRODUCTION}

The proximal carpectomy is a surgical procedure used in degenerative diseases of the wrist that preserves the possibility of movement. ${ }^{1-3}$ Indications are late conditions secondary to injury of the scapholunate ligament (scapholunate advanced collapse, SLAC); nonunion of scaphoid (scaphoid nonunion advanced collapse, SNAC); Kienböck disease; failure of implants to the scaphoid or lunate, and chronic perilunate dislocations..$^{1,4,5}$ Contraindications include chondral lesions in the proximal pole of the capitate or lunate fossa on the distal radius. ${ }^{6}$

The aim of this study was to analyze the functional results (range of motion and palmar grip strength) of patients undergoing proximal carpectomy in the treatment of traumatic or non-traumatic degenerative conditions of the wrist.

\section{MATERIALS AND METHODS}

This is a retrospective analysis of patients operated between February 2002 and February 2012, approved by the Institution's Ethics Committee under CAAE number 36705614.7.0000.5440. We evaluated 21 patients undergoing proximal carpectomy. Data were collected from medical records and functional assessments of patients by the Hand Therapy team in the preoperative, immediate postoperative and late postoperative period. The functional evaluation consisted of analogic goniometry of the active range of motion of the wrist (flexion, extension, radial deviation and ulnar deviation) and grip strength measured by a Jamar ${ }^{\circledR}$ dynamometer (USA) in the affected wrist and its contralateral side. Flexion and extension goniometry was performed with the goniometer's arms on the dorsal side of the third metacarpal and the other on the dorsal side of the radius. For measuring radial deviation and ulnar deviation, the center of the goniometer was placed on the head of the capitate on the dorsal surface of the wrist, one arm on the third metacarpal and the other on the dorsal side of radius. ${ }^{7}$ The measurement of strength was always made with the limb parallel to the upper torso, elbow in $90^{\circ}$ flexion, forearm and wrist in a neutral position and the dynamometer set at the second position (specific to assess grip strength) ${ }^{8,9}$ The simple arithmetic mean of three measurements with one minute interval between them, alternating between the dominant and non-dominant side was considered. For comparative analysis, we considered the measures made one week before the surgery and two years afterwards. Statistical analysis was performed using the non-parametric Wilcoxon-Mann-Whitney test for dependent variables, due to the small sample size. $p$-Value was calculated by normal approach.

\section{Surgical Technique}

All patients underwent anesthetic block of the brachial plexus and operated supine over a hand table. Venous drainage was gravitational and with the help of Esmarch bandage. The tourniquet was set at the arm level.

The access was longitudinal between the third and fourth extender compartments until exposure of the capsule, which was

All the authors declare that there is no potential conflict of interest referring to this article.

1. Universidade de São Paulo, Faculdade de Medicina de Ribeirão Preto, Hospital das Clínicas, Hand and Microsurgery Group, Ribeirão Preto, SP, Brasil.

Work developed at Universidade de São Paulo, Faculdade de Medicina de Ribeirão Preto, Hospital das Clínicas, Ribeirão Preto, SP, Brasil.

Correspondence: Hospital das Clínicas - Ortopedia, Av. Bandeirantes, 3900, 11 andar. Campus Universitário, 10048-900 Ribeirão Preto, SP, Brazil. Igmandarano@yahoo.com.br 
also split longitudinally. The articular surfaces were inspected to investigate possible chondral lesions, especially in the lunate fossa and the proximal pole of the capitate. Resection was always initiated by the lunate and pyramidal, and ended in the scaphoid, which was removed cutting to pieces with a gouge. Care was taken to preserve the volar radiocarpal ligaments, thus preventing possible ulnar translation of the carpal. In no case the distal pole of the scaphoid was left. Likewise, radial styloidectomy and neurectomy of the posterior interosseous nerve were also not performed in any case. After the removal of the tourniquet and hemostasis revision, the capsule was closed anatomically with non-absorbable thread, without bringing in the radiocarpal joint. Any kind of internal or external fixation was ever used. The volar splint, placed in the immediate postoperative period, was maintained in all cases for four to six weeks, when the movement of the wrist was started gradually, assisted by the Hand Therapy team. ${ }^{10}$

\section{RESULTS}

Of the 21 patients who underwent proximal carpectomy, six did not return for clinical evaluation, three requested discharge from the outpatient facility before completing one year after surgery and one died. In all, 11 patients completed follow-up and were followed until at least two years after surgery for functional evaluation. Of these, two were female and 9 male. Four patients had Kienböck disease (stage Illb) and seven presented non-union of the scaphoid (SNAC). The right side was affected eight times and left, three times. Only in two cases the affected side was not the dominant side. The mean age for the final functional evaluation, two years after surgery, was 42.6 years old.

\section{Statistical analysis}

Statistical analysis showed significant differences $(p<0.05)$ in the comparison of wrist flexion pre and postoperatively $(p-$ -value $=0.0006$ ); extension ( $p$-value $=0.0337$ ); ulnar deviation $(p=0.0289)$; grip strength ( $p$-value $=0.0006)$ and when comparing the contralateral wrist (not affected) and the operated wrist $(p$-value $=0.0002$ ). The evaluation of the contralateral wrist grip strength averaged $37.45 \mathrm{kgf}$, standard deviation $3.8 \mathrm{kgf}$, minimum $30 \mathrm{kgf}$, maximum $42 \mathrm{kgf}$ and a median of $38 \mathrm{kgf}$. There was no significant difference comparing radial deviation before and after surgery ( $p$-value $=0.3475$ ).

Tables 1-3 and Figures 1-6 present these data and those regarding measurement (goniometer and grip strength) pre and postoperative.

\section{DISCUSSION}

A Jamar ${ }^{\circledR}$ dynamometer (USA), recommended by the American Society of Hand Therapists and used in in most studies was used to assess grip strength. The second prehension position was used for all patients, since it facilitates the comparison of results between them and among other works in the literature. However, there is a possibility of adjusting the position according to the hand size of each individual.

We adopted a minimum interval of one minute between measurements to ensure that there was no influence of the factor muscle fatigue. We used simple arithmetic mean of the three measures. Caporrino et al. ${ }^{9}$ considered the highest mark achieved between the three measures. Probably the difference
Table 1. General data and functional results.

\begin{tabular}{c|c|c|c|c|c|c|c|c|c|c|c|c|c|c|c|c}
\hline & & & & & & Pre & & & & & Post & & & & Con \\
\hline Pat & Diag & $\begin{array}{c}\text { Gen } \\
\text { (years } \\
\text { old) }\end{array}$ & DS & AS & Flex & Ext & RD & UD & GS & Flex & Ext & RD & UD & GS & GS \\
\hline 1 & NUE & F & 24 & D & D & 20 & 20 & 8 & 20 & 18 & 80 & 70 & 10 & 20 & 28 & 32 \\
\hline 2 & NUE & M & 34 & D & D & 20 & 20 & 6 & 20 & 16 & 30 & 30 & 6 & 26 & 20 & 40 \\
\hline 3 & NUE & M & 45 & D & D & 10 & 30 & 8 & 30 & 24 & 30 & 30 & 8 & 40 & 36 & 38 \\
\hline 4 & DK & F & 58 & D & E & 34 & 20 & 10 & 10 & 20 & 38 & 20 & 10 & 30 & 30 & 30 \\
\hline 5 & DK & M & 43 & D & D & 10 & 8 & 0 & 0 & 14 & 12 & 8 & 0 & 10 & 20 & 38 \\
\hline 6 & NUE & M & 51 & D & D & 10 & 6 & 0 & 10 & 20 & 24 & 8 & 0 & 24 & 24 & 36 \\
\hline 7 & NUE & M & 34 & D & E & 10 & 10 & 4 & 10 & 18 & 40 & 30 & 8 & 26 & 24 & 42 \\
\hline 8 & NUE & M & 51 & D & D & 20 & 16 & 4 & 10 & 20 & 52 & 40 & 10 & 20 & 32 & 38 \\
\hline 9 & DK & M & 49 & D & D & 20 & 0 & 6 & 10 & 16 & 40 & 10 & 6 & 10 & 22 & 42 \\
\hline 10 & NUE & M & 44 & E & E & 10 & 10 & 4 & 10 & 16 & 38 & 48 & 4 & 10 & 22 & 40 \\
\hline 11 & DK & M & 36 & D & D & 8 & 14 & 6 & 8 & 18 & 24 & 30 & 6 & 16 & 22 & 36 \\
\hline
\end{tabular}

Pat: patient; Diag: diagnosis; Gen: gender; DS: dominant side; AS: affected side; Flex: flexion (degrees); Ext: extension (degrees); RD: radial deviation (degrees); UD: ulnar deviation ulnar (degrees); GS: Grip strength (kgf); Pre: preoperative; Post: postoperative; Con: contralateral wrist

Table 2. Combined preoperative results.

\begin{tabular}{c|c|c|c|c|c|c|c}
\hline Time & Variables & $\mathbf{n}$ & Mean & $\begin{array}{c}\text { Standard } \\
\text { deviation }\end{array}$ & Minimum & Median & Maximum \\
\hline \multirow{4}{*}{ Preop. } & Flex & 11 & 15.64 & 7.94 & 8.00 & 10.00 & 34.00 \\
\cline { 2 - 8 } & Ext & 11 & 14.00 & 8.34 & 0.00 & 14.00 & 30.00 \\
\cline { 2 - 8 } & RD & 11 & 5.09 & 3.14 & 0.00 & 6.00 & 10.00 \\
\cline { 2 - 8 } & UD & 11 & 12.55 & 7.95 & 0.00 & 10.00 & 30.00 \\
\cline { 2 - 8 } & GS & 11 & 18.18 & 2.75 & 14.00 & 18.00 & 24.00 \\
\hline
\end{tabular}

Preop: preoperative; Flex: flexion (degrees); Ext: extension (degrees); RD: radial deviation (degrees); UD: ulnar deviation ulnar (degrees); GS: Grip strength (kgf).

Table 3. Combined postoperative results.

\begin{tabular}{c|c|c|c|c|c|c|c}
\hline Time & Variables & $\mathbf{n}$ & Mean & $\begin{array}{c}\text { Standard } \\
\text { deviation }\end{array}$ & Minimum & Median & Maximum \\
\hline \multirow{7}{*}{ Postop. } & Flex & 11 & 37.09 & 17.76 & 12.00 & 38.00 & 80.00 \\
\cline { 2 - 8 } & Ext & 11 & 29.45 & 18.68 & 8.00 & 30.00 & 70.00 \\
\cline { 2 - 8 } & RD & 11 & 6.18 & 3.63 & 0.00 & 6.00 & 10.00 \\
\cline { 2 - 8 } & UD & 11 & 21.09 & 9.44 & 10.00 & 20.00 & 40.00 \\
\cline { 2 - 8 } & GS & 11 & 25.45 & 5.30 & 20.00 & 24.00 & 36.00 \\
\hline
\end{tabular}

Postop: postoperative; Flex: flexion (degrees); Ext: extension (degrees); RD: radial deviation (degrees); UD: ulnar deviation ulnar (degrees); GS: Grip strength (kgf).

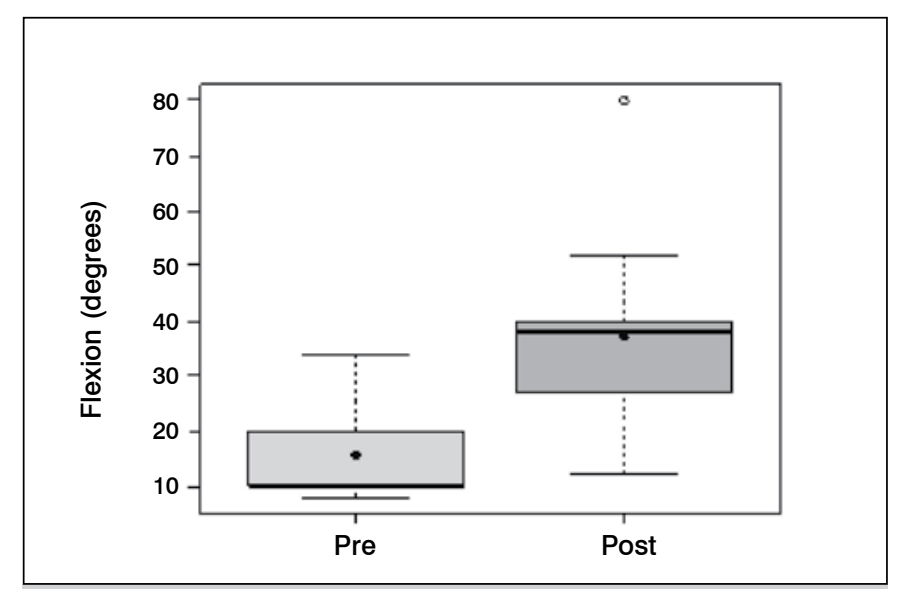

Figure 1. Boxplot comparing flexion of the wrist (degrees) preoperative and two years after surgery. 


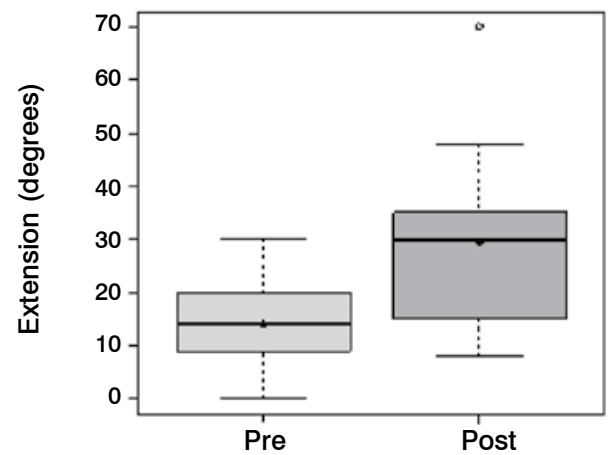

Figure 2. Boxplot comparing extension of the wrist (degrees) preoperative and two years after surgery.

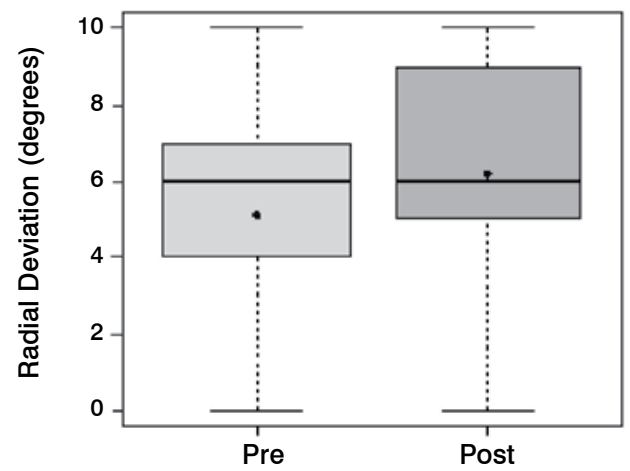

Figure 3. Boxplot comparing radial deviation of the wrist (degrees) preoperative and two years after surgery.

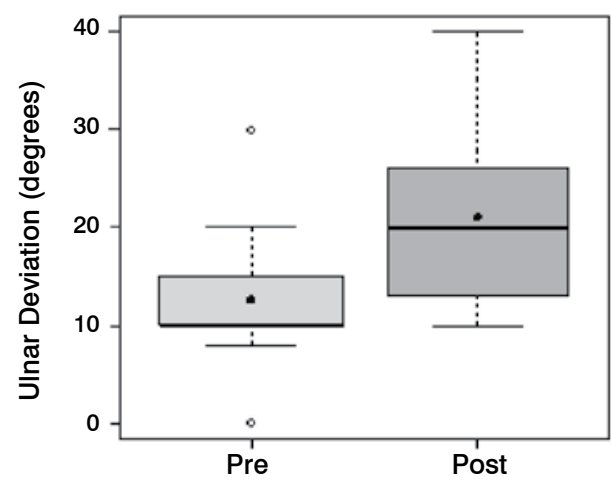

Figure 4. Boxplot comparing ulnar deviation of the wrist (degrees) preoperative and two years after.

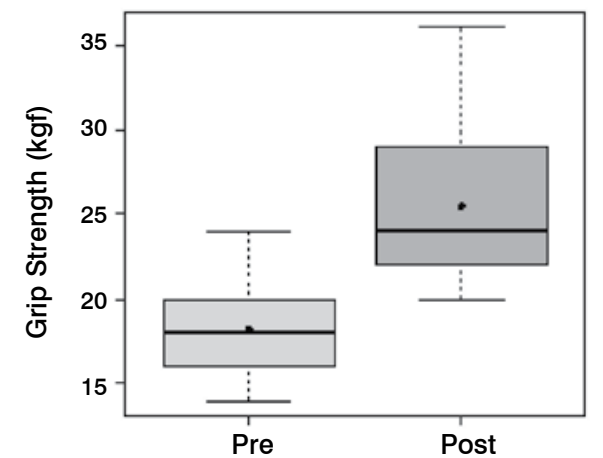

Figure 5. Boxplot comparing grip strength of the wrist (kgf) preoperative and two years after surgery.

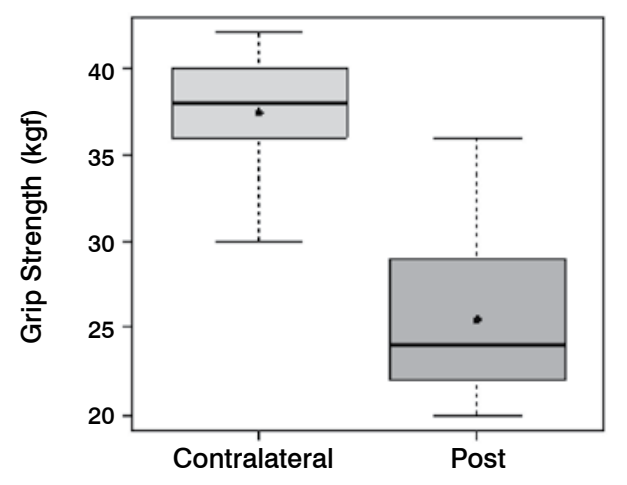

Figure 6. Boxplot comparing grip strength of the contralateral wrist (kgf) preoperative and two years after surgery.

between these methods is minimal and the important thing is to maintain the same measurement standard before and after surgery.

Of the 11 patients who were evaluated after two years of surgery, the causative basis of diagnosis of degenerative clinical handle frame was nonunion of scaphoid fractures (SNAC) and Kienböck disease. There were no cases secondary to the injury of scapholunate ligament (SLAC), which could be included in the functional evaluation. Other medical conditions where the proximal carpectomy can be indicated such as rheumatoid arthritis, flexion contractures (congenital or acquired), chronic perilunate dislocations and replantation were not observed, however, they would be excluded from the series according to their unique characteristics that hinder a comparative analysis. The data show that there was a significant improvement in the ability to actively bend $\left(15.6^{\circ}\right.$ to $\left.37.0^{\circ}\right)$ and extend (from $14.0^{\circ}$ to $\left.29.4^{\circ}\right)$ the wrist, and ulnar deviation $\left(12.5^{\circ}\right.$ to $\left.21.1^{\circ}\right)$. There was no significant gain in the radial deviation $\left(5.1^{\circ}\right.$ to $\left.6.2^{\circ}\right)$. The largest portion of the population shows flexion between $70-80^{\circ}$, 
and extension $60-70^{\circ}, 45^{\circ}$ ulnar deviation and $15^{\circ}$ radial deviation. ${ }^{7}$ The total range of motion for flexion-extension showed an average increase of $29.6^{\circ}$ to $66.4^{\circ}$, which represents a much better ability to spatial positioning of the hand and obvious functional gain. The pronosupination and goniometry of passive movement of the wrist were not evaluated in this study. Although not being fundamental parameters in this situation, they could enrich the final evaluation.

Grip strength also improved significantly, from $18.2 \mathrm{kgf}$ in the preoperative evaluation to $25.4 \mathrm{kgf}$ after two years of surgery. The comparison with the unaffected side shows that there is an important difference, since the average was $37.4 \mathrm{kgf}$. Population studies in our midst show that the difference between the dominant and non-dominant hand is around 10 to $12 \% .{ }^{10}$

Pre and postoperative pain has not been systematically evaluated with visual or numerical scales. After two years of surgery, according to medical records, five patients (46\%) had no pain or pain was reported as mild and tolerable and went back to work. There is no reference to the type of work or if there was function exchange. Three patients $(27 \%)$ had pain equal to the preoperative situation, but did not want another surgery. Of these, two returned to work; there is no information about the third. Three patients (27\%) had worsened pain relative to baseline, one of which evolved with clinical signs compatible with complex regional pain syndrome. These three cases were subsequently submitted to total wrist arthrodesis.

Our results show correspondence to other studies with higher postoperative follow-ups; ${ }^{1,3,11}$ and comparisons between techniques. ${ }^{2,5}$

Auxiliary surgical techniques can bring improvement in pain symptoms, such as the interposition of the volar capsule, ${ }^{12}$ osteochondral grafts ${ }^{13}$ and posterior interosseous neurectomy, however, they were not used in this series. Further studies should be conducted to compare the results of the association or not of these procedures, as well as the proximal arthroscopic carpectomy. ${ }^{14}$

Function scores (DASH, QuickDASH, MHQ - Michigan Hand Questionaire $^{15}$ and MWS-Mayo Wrist Score ${ }^{16}$ ) and radiographic review for staging of osteoarthritis radiocapitate ${ }^{6,17}$ can also be used in future studies as a way to refine the evaluation of results in the medium and long term.

\section{CONCLUSION}

The proximal carpectomy is an alternative in the treatment of degenerative disorders of the wrist, improving range of motion and grip strength, when compared to preoperative status.

\section{REFERENCES}

1. Wall LB, Didonna ML, Kiefhaber TR, Stern PJ. Proximal row carpectomy: minimum 20-year follow-up. J Hand Surg Am. 2013;38(8):1498-504.

2. Zinberg EM, Chi Y. Proximal row carpectomy versus scaphoid excision and intercarpal arthrodesis: intraoperative assessment and procedure selection. J Hand Surg Am. 2014;39(6):1055-62.

3. Chim H, Moran SL. Long-term outcomes of proximal row carpectomy: a systematic review of the literature. J Wrist Surg. 2012;1(2):141-8.

4. Godinho DR, Barros F, Barros F, Argotte W. Carpectomia proximal. Rev Bras Ortop. 1996;31(3):225-30.

5. Severo LA, Costa M, Lopes Junior OV, Piluski $P$, Lech O. Análise funcional da artrodese dos quatro cantos comparada com a carpectomia proximal. Rev Bras Ortop. 2006:41:14-21.

6. Culp RW, McGuigan FX, Turner MA, Lichtman DM, Osterman AL, McCarroll HR. Proximal row carpectomy: a multicenter study. J Hand Surg Am. 1993;18(1):19-25.

7. Pardini Júnior AG. Punho. In: Barros Filho TEP, Lech O. Exame físico em ortopedia. São Paulo: Sarvier; 2002. p. 157-70.

8. Silva JB, Del Rio JT, Fernandes HF, Diniz S, Fridman M. Carpectomia proximal do carpo na artrose radioescafolunar. Rev Bras Ortop. 1997;32(11):894-8.

9. Caporrino FA, Faloppa F, Santos JBG, Ressio C, Soares FHC, Nakachima LR, et al. Estudo populacional da força de preensão palmar com dinamômetro Jamar $^{\circledR}$. Rev Bras Ortop. 1998;33(2):150-4.

10. Stern PJ, Agabegi SS, Kiefhaber TR, Didonna ML. Proximal row carpectomy. J Bone Joint Surg Am. 2005 ;87(Suppl 1)(Pt 2):166-74.

11. Ali MH, Rizzo M, Shin AY, Moran SL. Long-term outcomes of proximal row carpectomy: a minimum of 15-year follow-up. Hand (NY). 2012;7(1):72-8.

12. Kwon BC, Choi SJ, Shin J, Baek GH. Proximal row carpectomy with capsular interposition arthroplasty for advanced arthritis of the wrist. J Bone Joint Surg Br. 2009;91(12):1601-6.

13. Fowler JR, Tang PC, Imbriglia JE. Osteochondral resurfacing with proximal row carpectomy: 8-year follow-up. Orthopedics. 2014;37(10):e856-9.

14. Weiss ND, Molina RA, Gwin S. Arthroscopic proximal row carpectomy. J Hand Surg Am. 2011;36(4):577-82.

15. Chung KC, Pillsbury MS, Walters MR, Hayward RA. Reliability and validity testing of the Michigan Hand Outcomes Questionnaire. J Hand Surg Am. 1998;23(4):575-87.

16. Amadio PC, Berquist TH, Smith DK, Ilstrup DM, Cooney WP 3rd, Linscheid RL. Scaphoid malunion. J Hand Surg Am. 1989;14(4):679-87.

17. Jebson PJ, Hayes EP, Engber WD. Proximal row carpectomy: a minimum 10-year follow-up study. J Hand Surg Am. 2003;28(4):561-9. 